Article

\title{
Influence of Anodization Temperature on Geometrical and Optical Properties of Porous Anodic Alumina(PAA)-Based Photonic Structures
}

\author{
Ewelina Białek ${ }^{1}$, Maksymilian Włodarski ${ }^{2}$ and Małgorzata Norek ${ }^{1, *(1)}$ \\ 1 Institute of Materials Science and Engineering, Faculty of Advanced Technologies and Chemistry, \\ Military University of Technology, Str. gen Sylwestra Kaliskiego 2, 00-908 Warsaw, Poland; \\ ewelina.bialek2@gmail.com \\ 2 Institute of Optoelectronics, Military University of Technology, Str. gen. Sylwestra Kaliskiego 2, \\ 00-908 Warsaw, Poland; maksymilian.wlodarski@wat.edu.pl \\ * Correspondence: malgorzata.norek@wat.edu.pl
}

Received: 23 June 2020; Accepted: 13 July 2020; Published: 16 July 2020

check for updates

\begin{abstract}
In this work, the influence of a wide range anodizing temperature $\left(5-30{ }^{\circ} \mathrm{C}\right)$ on the growth and optical properties of PAA-based distributed Bragg reflector (DBR) was studied. It was demonstrated that above $10{ }^{\circ} \mathrm{C}$ both structural and photonic properties of the DBRs strongly deteriorates: the photonic stop bands (PSBs) decay, broaden, and split, which is accompanied by the red shift of the PSBs. However, at $30^{\circ} \mathrm{C}$, new bands in transmission spectra appear including one strong and symmetric peak in the mid-infrared (MIR) spectral region. The PSB in the MIR region is further improved by a small modification of the pulse sequence which smoothen and sharpen the interfaces between consecutive low and high refractive index layers. This is a first report on PAA-based DBR with a good quality PSB in MIR. Moreover, it was shown that in designing good quality DBRs a steady current recovery after subsequent application of high potential $\left(\mathrm{U}_{\mathrm{H}}\right)$ pulses is more important than large contrast between low and high potential pulses $\left(\mathrm{U}_{\mathrm{H}}-\mathrm{U}_{\mathrm{L}}\right.$ contrast). Smaller $\mathrm{U}_{\mathrm{H}}-\mathrm{U}_{\mathrm{L}}$ contrast helps to better control the current evolution during pulse anodization. Furthermore, the lower PSB intensity owing to the smaller $\mathrm{U}_{\mathrm{H}}-\mathrm{U}_{\mathrm{L}}$ contrast can be partially compensated by the higher anodizing temperature.
\end{abstract}

Keywords: porous anodic alumina (PAA); pulse anodization; distributed Bragg reflector (DBR); PAA-based DBR; transmission spectra; photonic stop band (PSB); temperature

\section{Introduction}

Porous anodic alumina (PAA) is a multifunctional porous ceramic coating prepared by anodization of aluminum. Its geometrical parameters, such as interpore distance $\left(D_{c}\right)$ and pore diameter $\left(D_{p}\right)$, can be controlled by electrochemical conditions including type and concentration of electrolyte, temperature, applied voltage, and anodization time [1,2]. PAA with long-range hexagonally ordered and parallel pores is usually formed under self-ordering regimes, which are defined by narrow process windows characteristic for a given electrolyte [3,4]. Out of these regimes, the pore arrangement strongly deteriorates. The best hexagonal pore ordering is, however, obtained upon anodization conducted close to the so-called critical voltage, where high current/high electric field strength conditions are operative [5,6]. The larger the dissociation constant for a given electrolyte, the lower is the critical voltage [7]. Stability of the anodization is regulated also by temperature: the higher the temperature, the lower the critical voltage. The applied voltage determines mostly the $D_{c}[8,9]$, while temperature-both $D_{c}$ and $D_{p}[10,11]$. Porosity of PAA is related to both interpore distance and pore diameter via 
the equation: $P=\frac{\pi}{2 \sqrt{3}}\left(\frac{D_{p}}{D_{c}}\right)^{2}$ [12]. PAA can be used as a template to fabricate various functional nanostructures [13-15] or itself is a functional material used in gas separation [16], medicine (tissue engineering) [17], or electronics (supercapacitors) [18]. One of the recent applications of PAA is related with a possibility to engineer PAA-based photonic structures.

The photonic structures based on porous materials are usually one-dimensional (1D) photonic crystals (PCs) built of many alternating low and high refractive index (RI) layers and the thickness adequate to obtain the enhancement of a selected wavelength $(\lambda)$, as a result of constructive interference of waves reflected from the interface between the neighboring layers (the photonic stopband, PSB) $[19,20]$. The PSB is thus related to the wavelength ranges where the material demonstrates high reflectivity and low transmittance of light. The refractive index of porous layer is strictly related with its porosity $(P)$ : RI decreases as $P$ increases [21]. Therefore, one of the important issue in designing this type of photonic crystals is a precise control over the porosity of the alternating and subsequent layers. The larger the refractive index contrast (the difference between the low and high RI of alternating layers), the more light is reflected from the layer boundary, and the more intensive PSB at a given $\lambda$ can be obtained. Spectral position of PSB is very sensitive to a slight change of refractive index of a medium, and this property is a base for engineering a broad range of optical sensors [22-25].

To obtain PAA with periodically variable porosity of alternating layers, pulse anodization is applied which relies on periodic change of anodization parameters, such as voltage or current density [26,27]. The pulse sequence can be modified accordingly (different anodization modes, different current/voltage values of the generated cycles, various shape of the pulses including saw-like or pseudo-stepwise anodization waves, various ramp rate between high $\left(\mathrm{U}_{\mathrm{H}}\right)$ and low potential $\left(\mathrm{U}_{\mathrm{L}}\right)$, different duration of the pulses, variable number of pulses, etc.) to design a desired pore architecture and to mold strong and narrow resonances at a given spectral range. During pulse anodization other factors-such as electrolyte composition, concentration, and temperature-need to be carefully selected in order to maintain the self-ordering conditions without uncontrolled pore branching, or burning effects. PAA-based PCs developed so far were synthesized prevalently in sulfuric [28-32] and oxalic [33-36] electrolytes, using galvanostatic (current density control) or potentiostatic (voltage control) mode. First pulse anodization experiments in oxalic acid appeared to be quite challenging as compared to those in sulfuric acid owing to a relatively dense and compact barrier layer formed under high potential pulses $\left(\mathrm{U}_{\mathrm{H}}=55 \mathrm{~V}\right)$ [37]. The dense barrier layer prevented passage of ions under application of subsequent low potential pulses $\left(\mathrm{U}_{\mathrm{L}}=40 \mathrm{~V}\right)$ [37]. However, it was later shown that a uniform growth of alternating low and high RI layers is also possible upon application of a stepwise decrease of $U_{H}$ to $\mathrm{U}_{\mathrm{L}}$, which allowed for a continuous barrier layer thinning [34]. Moreover, thanks to the application of a suitable voltage ramp rate, it was possible to increase the contrast between the $U_{H}(50 \mathrm{~V})$ and $U_{L}$ $(20 \mathrm{~V})$ potentials, which translates into the larger refractive index contrast. Since then the influence of various pulse profiles [38,39], durations and amplitudes [40] on PAA-based PCs architecture and optical properties was studied. The optical properties of PAA-based photonic crystals were also tuned via application of mixed oxalic and phosphoric acid concentrations [41]. Mixing different concentration of phosphoric acid $(0.05,0.1,0.2$, and $0.3 \mathrm{M})$ with $0.3 \mathrm{M}$ oxalic acid solution has allowed to expand the amplitudes of the applied voltage pulses (up to $\mathrm{U}_{\mathrm{HA}}=100 \mathrm{~V}$ ) and to improve the PSB signal quality (smaller full width at half maximum, FWHM, and greater intensity). Despite quite extensive research on the impact of various parameters on optical properties of PAA-based PCs, little attention was paid so far to anodizing temperature, although it is a very important factor governing the growth rate of PAA layers. Furthermore, it is expected that apart from increasing the reaction speed other parameters, such as pore regularity and circularity, will be improved at higher temperatures [10]. This, in turn, should have a beneficial effect on the quality of PSBs. The photonic properties of PAA-based photonic structures were previously studied in a narrow temperature range $\left(6-18^{\circ} \mathrm{C}\right.$ in [42] and $8-11^{\circ} \mathrm{C}$ in [43]). However, it is of great interest to systematically study the impact of temperature on the properties of PAA-based PCs in a much broader range. 
In this work, we analyze the impact of temperature on the quality of the PAA-based distributed Bragg reflector (DBR) structure fabricated in oxalic electrolyte in the temperature range $5-30{ }^{\circ} \mathrm{C}$. The impact of temperature on spectral position and intensity of PSB is systematically analyzed. It is shown that in this temperature range the photonic properties of PAA-based DBR change immensely. The PSB resonances worsen at the temperature $>10^{\circ} \mathrm{C}$ : the resonance peaks in transmission spectra fade away, broaden, and split, which is accompanied by the red shift of PSBs. However, at $30{ }^{\circ} \mathrm{C}$, the peaks appear again with a strong and symmetric PSB in the mid-infrared (MIR) spectral region. Moreover, the photonic properties in the MIR are improved by a small modification of pulse sequence which sharpens the boundaries between low and high RI segments in PAA. This is a first report on production of PAA-based DBR with a good quality PSB in MIR. The results obtained in this work can extend the application of the PAA-based photonic structures up to the MIR spectral range.

\section{Materials and Methods}

The PAA-based distributed Bragg reflector (DBR) structures were synthesized by a pulse anodization of aluminum. High-purity aluminum foil (99.9995\% Al, Puratronic, Alfa-Aesar, Haverhill, MA, USA) with a thickness of about $0.25 \mathrm{~mm}$ was cut into specimens $(2 \mathrm{~cm} \times 1 \mathrm{~cm})$. Before the anodization process the $\mathrm{Al}$ foils were annealed under argon atmosphere at $400{ }^{\circ} \mathrm{C}$ for $2 \mathrm{~h}$. Then the samples were degreased in acetone and ethanol and subsequently electropolished in a 1:4 mixture of $60 \% \mathrm{HClO}_{4}$ and ethanol at $0{ }^{\circ} \mathrm{C}$, under constant voltage of $25 \mathrm{~V}$, at $1{ }^{\circ} \mathrm{C}$, and for $2.5 \mathrm{~min}$. Next, the samples were rinsed with a distilled water, then ethanol, and dried. As prepared $\mathrm{Al}$ specimens were insulated at the back and the edges with acid resistant tape, and serve as the anode. A Pt grid was used as a cathode and the distance between both electrodes was kept constant $(\mathrm{ca} .5 \mathrm{~cm})$. A large, $1 \mathrm{~L}$ electrochemical cell, a powerful low-constant-temperature bath, and vigorous stirring ( $500 \mathrm{rpm}$ ) were employed in the anodizing process. Programmable DC power supply, model 62012P-600-8 Chroma, was used to control the applied voltage and the pulse parameters. The first anodization was carried out at $5{ }^{\circ} \mathrm{C}$ in $0.3 \mathrm{M} \mathrm{C}_{2} \mathrm{H}_{2} \mathrm{O}_{4}$ water-based solution, at $40 \mathrm{~V}$, for $20 \mathrm{~h}$. As obtained alumina was chemically removed in a mixture of $6 \mathrm{wt} \%$ phosphoric acid and $1.8 \mathrm{wt} \%$ chromic acid at $60{ }^{\circ} \mathrm{C}$ for $3 \mathrm{~h}$. Subsequently, pulse anodization with 20 cycles was conducted at the temperature range $5-30{ }^{\circ} \mathrm{C}$. In general, a pulse cycle consisted of three steps: (1) a constant high voltage step $\left(U_{H}=50,45,40 \mathrm{~V}\right)$ applied for $360 \mathrm{~s}$; (2) a gradual reduction of the voltage to $20 \mathrm{~V}$ (and to $30 \mathrm{~V}$ ) at rates of $0.312,0.234,0.156$, and $0.078 \mathrm{~V} / \mathrm{s}$ (and at $0.07 \mathrm{~V} / \mathrm{s}$, respectively); (3) the anodization at a constant low voltage $\left(\mathrm{U}_{\mathrm{L}}=20 \mathrm{~V}\right)$ for $480 \mathrm{~s}$ (one sample was anodized under $\mathrm{U}_{\mathrm{L}}=30 \mathrm{~V}$ and the pulse duration of $3600 \mathrm{~s}$ ). After the pulse anodization was completed, the remaining aluminum substrate was selectively removed in a saturated solution of $\mathrm{HCl} / \mathrm{CuCl}_{2}$.

Structural characterization of the PAA-based photonic structures was made using a field-emission scanning electron microscope FE-SEM (AMETEK, Inc., Mahwah, NJ, USA) equipped with energy dispersive X-ray spectrometer (EDS). The measurement of layer thickness was repeated three times at different points in the image of a given PAA sample and an average of the three measurements was taken to determine the initial and final $d_{H}$ and $d_{L}$ thickness and the total thickness of the PAA membrane $\left(d_{\text {tot }}\right)$.

The transmission spectra were measured with two instruments. Shortwave end of the spectrum (250-2500 nm) was measured by Cary 5000 spectrometer with DRA-2500 integrating sphere from Agilent Technologies Inc., Santa Clara, CA, USA. Longwave end of the spectrum (2500-25,000 nm) was measured by Fourier-transform infrared (FTIR) spectrometer Alpha II from Bruker Corp., Billerica, MA, USA. The resolution of spectra was set to $1 \mathrm{~nm}$ in shortwave range and $2 \mathrm{~cm}^{-1}$ in longwave range.

\section{Results and Discussion}

Current density $\left(i_{a}\right)$-time $(t)$ transients during pulse anodization (20 cycles) of aluminum at temperature (T) between $5-30{ }^{\circ} \mathrm{C}$ are shown in Figure 1a. The PAA-based DBR is formed by applying a series of potential pulses, comprising high potential pulse $\left(\mathrm{U}_{\mathrm{H}}=50 \mathrm{~V}\right.$ and $\left.\mathrm{t}_{\mathrm{H}}=360 \mathrm{~s}\right)$ followed by a low 
potential pulse $\left(\mathrm{U}_{\mathrm{L}}=20 \mathrm{~V}\right.$ and $\left.\mathrm{t}_{\mathrm{L}}=480 \mathrm{~s}\right)$. First three pulse profiles $(\mathrm{U}(\mathrm{V}))$ together with $i_{a}(t)$ curves recorded at $5{ }^{\circ} \mathrm{C}$ and $30^{\circ} \mathrm{C}$ are demonstrated in Figure $1 \mathrm{~b}$. It can be seen that the current characteristics changes with temperature. At relatively low temperatures $\left(5-15^{\circ} \mathrm{C}\right)$, after application of $\mathrm{U}_{\mathrm{H}}$ pulse, the current recovery effect is typical for conventional mild anodization (MA) processes, where current is large at the initial stage, goes to a minimum value passing through a current pike, and then increases gradually to reach a steady value. However, at higher temperature $\left(20-30{ }^{\circ} \mathrm{C}\right)$ upon applying the $\mathrm{U}_{\mathrm{H}}$ pulse, the current increases steeply for a short period of time and then decreases exponentially. The latter behavior is typical for hard anodization (HA) processes. The current recovery peak $\left(i_{a}{ }^{\max }\right)$ after application of the successive $U_{H}$ pulses starts to decay visibly for the samples anodized at $\mathrm{T}>10{ }^{\circ} \mathrm{C}$. At $30^{\circ} \mathrm{C}$, the last current recovery peak is about $30 \%$ less intensive than the first one.
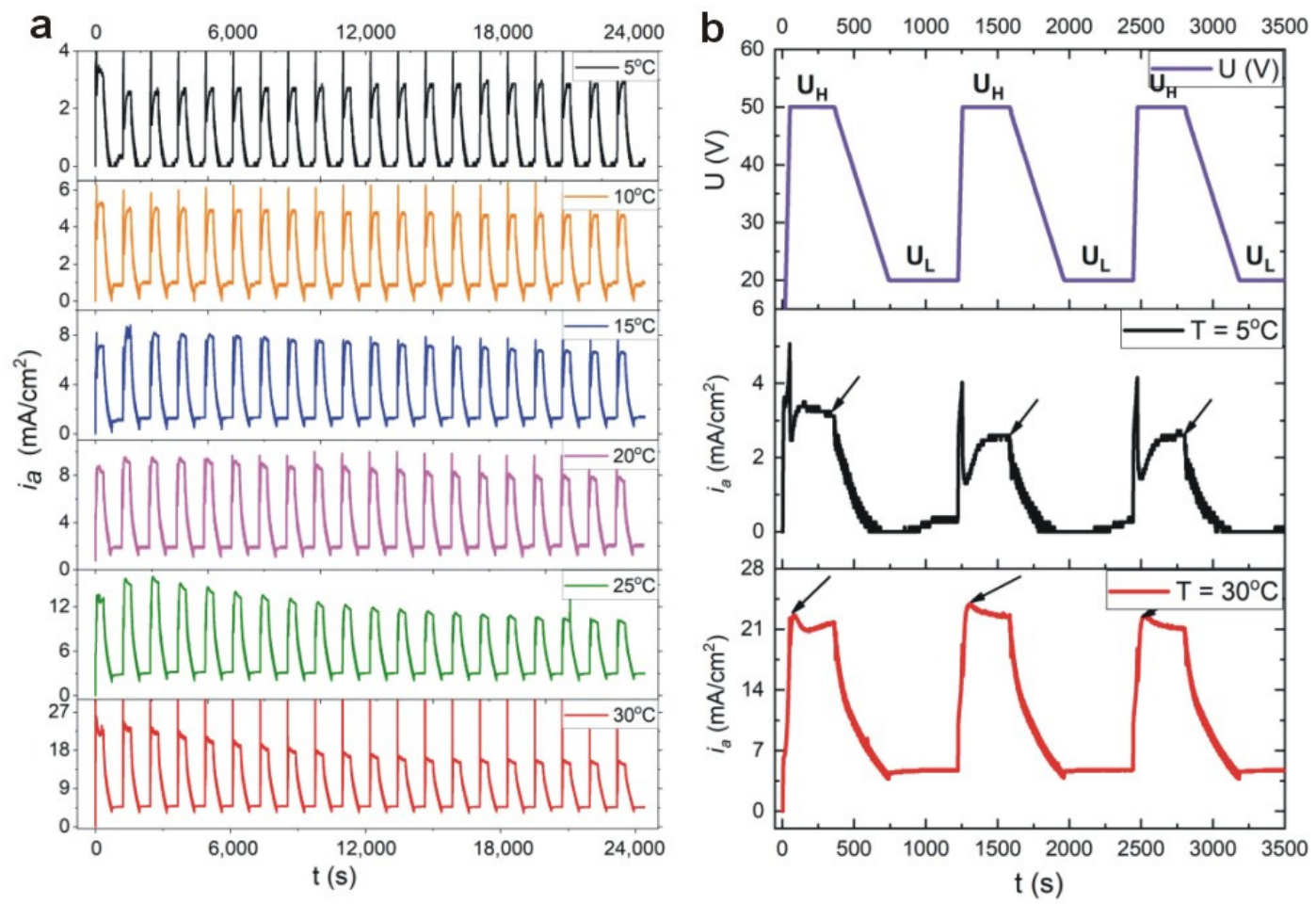

Figure 1. Current density $\left(i_{a}\right)$-time $(t)$ transients during pulse anodization (20 cycles) of aluminum at temperatures $5-30{ }^{\circ} \mathrm{C}(\mathbf{a})$; first three $\mathrm{U}_{\mathrm{H}}-\mathrm{U}_{\mathrm{L}}$ pulses along with the $i_{a}(t)$ curves for anodization at $5{ }^{\circ} \mathrm{C}$ and $30^{\circ} \mathrm{C}(\mathbf{b})$. The black arrows in Figure $1 \mathrm{~b}$ signify the $i_{a}{ }^{\text {max }}$ : depending on the type of anodization process (MA or HA) the $i_{a}{ }^{m a x}$ value was determined at the end or the beginning of the $\mathrm{U}_{\mathrm{H}}$ pulse.

The unequal current recovery indicates that the total amount of charge in each $\mathrm{U}_{\mathrm{H}}$ pulse decreases as the number of pulses increases. Since the thickness of anodic alumina is directly proportional to the net amount of charge involved in anodization reaction, it is thus expected that anodic alumina formed under the present conditions will contain segments with non-uniform thickness. Thickness of three initial and final segments (corresponding with the first and last potential pulses in the 20-cycle anodization process) formed under $\mathrm{U}_{\mathrm{H}}$ and $\mathrm{U}_{\mathrm{L}}$ potentials $\left(\mathrm{d}_{\mathrm{H}}\right.$ and $\mathrm{d}_{\mathrm{L}}$, respectively) for PAA produced at the two extreme temperatures is presented in Figure 2. As can be seen, the difference between initial and final $\mathrm{d}_{\mathrm{H}}$ and $\mathrm{d}_{\mathrm{L}}$ segments is much larger in the PAA-based DBR formed at $30{ }^{\circ} \mathrm{C}$ as compared to that formed at $5{ }^{\circ} \mathrm{C}$. 

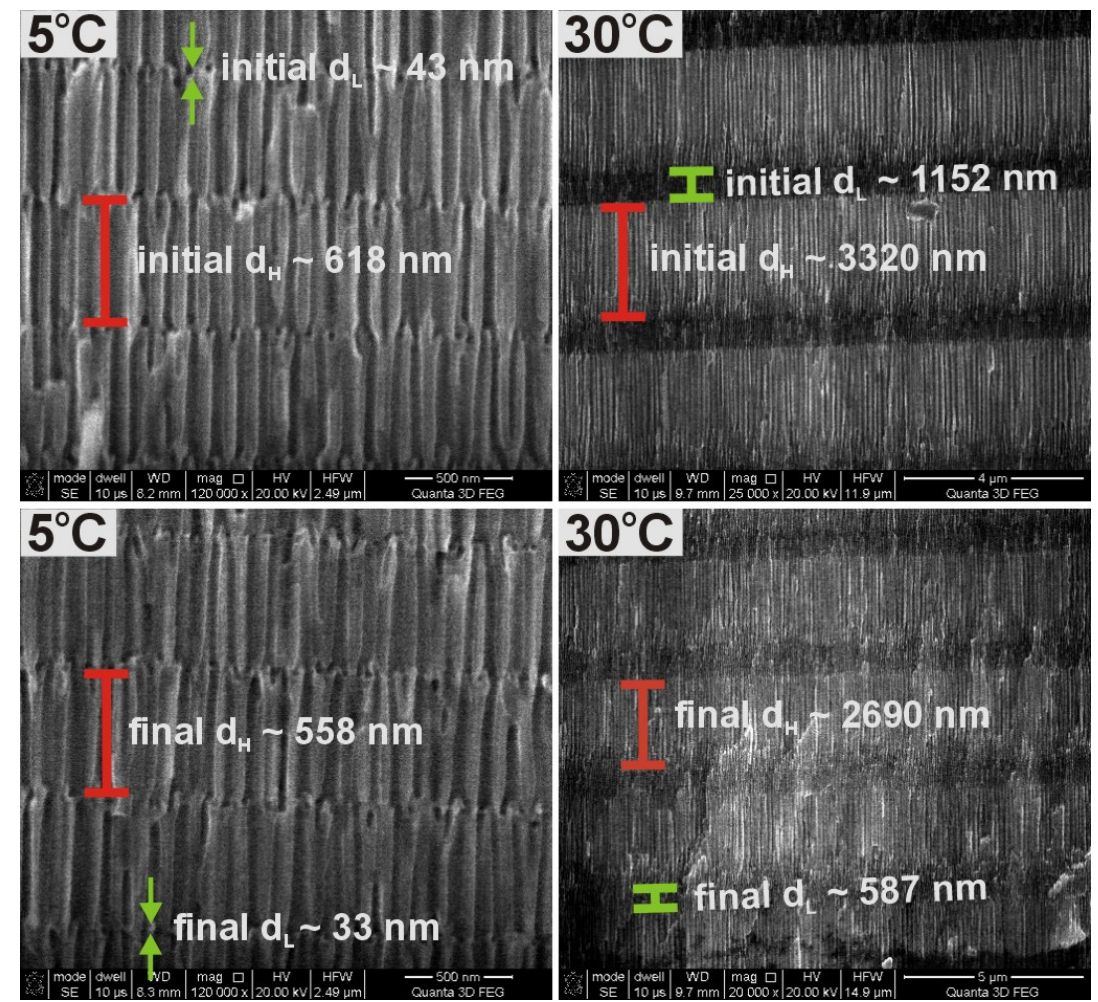

Figure 2. SEM images of a cross sectional view of the initial and final PAA segments obtained during the pulse anodization at $5{ }^{\circ} \mathrm{C}$ (the sample PAA $-5^{\circ} \mathrm{C}$ ) and $30^{\circ} \mathrm{C}$ (the sample PAA- $30^{\circ} \mathrm{C}$ ).

The evolution of $i_{a}{ }^{\max }$ (indicated by black arrows in Figure $1 \mathrm{~b}$ ) after application of the following $20 \mathrm{U}_{\mathrm{H}}$ pulses for all samples anodized at temperatures $5-30{ }^{\circ} \mathrm{C}$ is well visible in Figure $3 \mathrm{a}$. At $5{ }^{\circ} \mathrm{C}$ and $10^{\circ} \mathrm{C}$, the $i_{a}{ }^{m a x}$ remains more or less at stable values during each cycle of anodizing, however, starting already from $15^{\circ} \mathrm{C}$ the $i_{a}{ }^{m a x}$ gets weakened noticeably as the number of $\mathrm{U}_{\mathrm{H}}$ pulses increase. At $25^{\circ} \mathrm{C}$ and $30^{\circ} \mathrm{C}$, the $i_{a}{ }^{\max }$ intensity drop is very significant. The behavior is followed by the increasing difference between initial and final $\mathrm{d}_{\mathrm{H}}$ and $\mathrm{d}_{\mathrm{L}}$ layers (Figure $3 b$ ). First of all, an increase of temperature results in thicker $d_{H}$ and $d_{L}$ slabs owing to the enhanced electrochemical reaction rate. The $d_{L}$ difference is rather negligible in the temperature range $5-25^{\circ} \mathrm{C}$ but starts to be pronounced at $30{ }^{\circ} \mathrm{C}$. However, the difference between first and last $\mathrm{d}_{\mathrm{H}}$ segments begins to grow substantially already at $\mathrm{T}$ $>10{ }^{\circ} \mathrm{C}$. The effect indicates the appearance of diffusional problems at the higher temperatures related with the extended diffusion path along the nanopores and consequently slower mass transport (the oxygen-containing anionic species such as $\mathrm{O}^{2-}, \mathrm{OH}^{-}$) from the electrolyte to the pore bottom [44-46]. Nevertheless, the total thickness ( $d_{\text {tot }}$ ) of PAA dependence on temperature (in the $5-25^{\circ} \mathrm{C}$ range) is almost linear (Figure 3c) what suggests that other, rate-limiting processes have to be also accounted for this behavior. The $\mathrm{d}_{\mathrm{tot}}$ of PAA prepared at $30^{\circ} \mathrm{C}$ is an exception here. The sudden collapse of the linear relationship for this sample could indicate the existence of a boundary thickness (around $54 \mu \mathrm{m}$ ), above which $\mathrm{Al}_{2} \mathrm{O}_{3}$ stops to grow. 

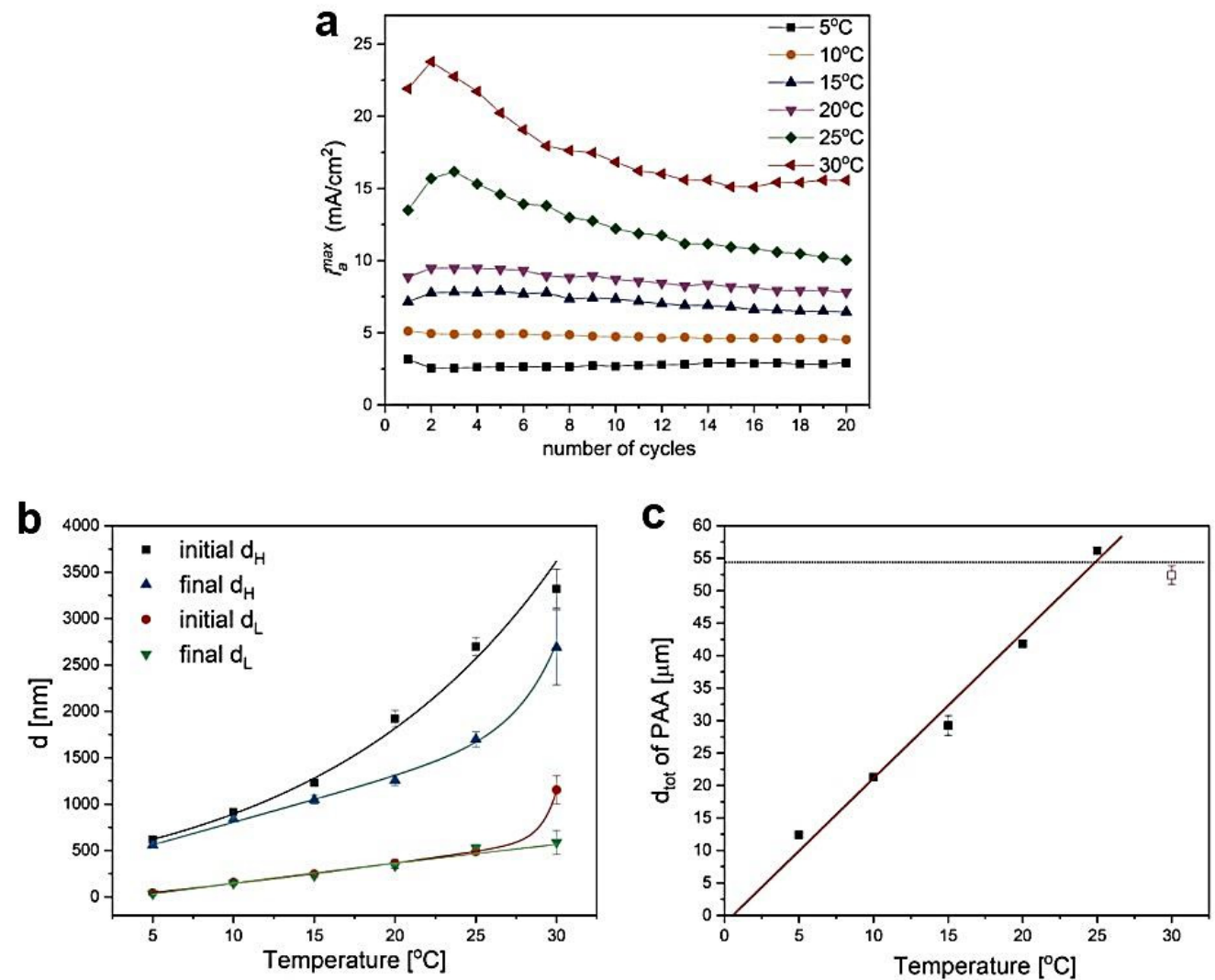

Figure 3. $i_{a}{ }^{\text {max }}$ as a function of the number of cycles (a) thickness of initial and final $\mathrm{d}_{\mathrm{H}}$ and $\mathrm{d}_{\mathrm{L}}$ segments as a function of anodizing temperature $(b)$ total thickness $\left(d_{t o t}\right)$ of PAA membranes as a function of anodization temperature (c).

To get deeper insight into this issue, additional PAA-based DBR structure under the following anodizing conditions was prepared: $\mathrm{U}_{\mathrm{H}}=50 \mathrm{~V}$ with $\mathrm{t}_{\mathrm{H}}=360 \mathrm{~s}$, and $\mathrm{U}_{\mathrm{L}}=30 \mathrm{~V}$ with $\mathrm{t}_{\mathrm{L}}=3600 \mathrm{~s}$. In order to avoid too extensive PAA growth, the process was conducted at $10^{\circ} \mathrm{C}$ (therefore the sample will be further named as \#PAA- $\left.10^{\circ} \mathrm{C}\right)$. The $i_{a}(t)$ curves recorded during anodization of \#PAA- $10{ }^{\circ} \mathrm{C}$ and PAA $-30^{\circ} \mathrm{C}$ samples are compared in Figure 4 a. Despite prolonged anodization time of the \#PAA-10 ${ }^{\circ} \mathrm{C}$ sample (the whole process lasted ca. $24 \mathrm{~h}$ ), the $i_{a}{ }^{\max }$ remains at quite stable values after application of subsequent $\mathrm{U}_{\mathrm{H}}$ pulses (the recovery of current after application of the $\mathrm{U}_{\mathrm{L}}$ pulses is very regular), in contrast to the $i_{a}{ }^{\max }$ recorded during pulse anodization of the sample PAA- $-30{ }^{\circ} \mathrm{C}$. As an effect of the steady current evolution, the thickness of initial and final $d_{H}$ and $d_{L}$ segments in the sample \#PAA $-10^{\circ} \mathrm{C}$ does not differ so much as in the sample PAA $-30^{\circ} \mathrm{C}$ (Figure $4 \mathrm{~b}, \mathrm{c}$ ). Particularly, the thickness of initial $d_{L}$ layers is larger only of about $7 \%$ from that of the final ones. Closer examination of the sample PAA- $30{ }^{\circ} \mathrm{C}$ revealed that it is built only out of $15 \mathrm{~d}_{\mathrm{L}}$ and $\mathrm{d}_{\mathrm{H}}$ layers instead of 20 , which explains its lower $d_{\text {tot }}(\sim 52 \mu \mathrm{m})$ than expected (Figure $\left.4 \mathrm{~d}\right)$. The resulted $\mathrm{d}_{\text {tot }}$ of the \#PAA- $10{ }^{\circ} \mathrm{C}$ is ca. $9 \mu \mathrm{m}$ thicker $\left(\mathrm{d}_{\text {tot }} \sim 61 \mu \mathrm{m}\right)$ than the PAA $-30^{\circ} \mathrm{C}$ (Figure 4e). Moreover, despite the larger thickness of the membrane, the \#PAA- $10{ }^{\circ} \mathrm{C}$ photonic crystal consists of full $20 \mathrm{~d}_{\mathrm{L}}$ and $\mathrm{d}_{\mathrm{H}}$ layers (Figure $4 \mathrm{e}$ ). It is therefore evident that the growth of the remaining $5 \mathrm{~d}_{\mathrm{H}}$ and $\mathrm{d}_{\mathrm{L}}$ layers in the PAA- $30{ }^{\circ} \mathrm{C}$ sample was not stopped solely by diffusional problems related with too thick membrane. Moreover, successful formation of the 15 subsequent $t_{\mathrm{H}}$ and $t_{\mathrm{L}}$ layers in PAA- $30{ }^{\circ} \mathrm{C}$ DBR indicates that the mass transport (movement of ionic species, such as $\mathrm{O}^{2-}, \mathrm{OH}^{-}, \mathrm{Al}^{3+}$ through the barrier layer) was not hindered by a too thick barrier layer formed at the high temperature. On the contrary, the high temperature provided sufficient driving force to overcome this barrier. Most probably a high reaction rate, which requires a continuous and relatively fast delivery of the anionic species from the bulk reservoir to the pore basis (from the electrolyte to the oxide/metal interface), was mainly responsible for reaction 
termination during pulse anodization at $30^{\circ} \mathrm{C}$. The electrochemical formation of PAA is determined by both diffusion-controlled and rate-controlled processes. If the PAA thickness is increased too much, the delivery is substantially delayed, and the electrochemical reaction at $30^{\circ} \mathrm{C}$ is terminated due to the high reaction speed. In the case of the sample \#PAA- $10^{\circ} \mathrm{C}$ the reaction rate is slowed down so much that the larger distances that ions have to overcome along the increasing thickness of PAA does not constitute an obstacle in the oxide formation.
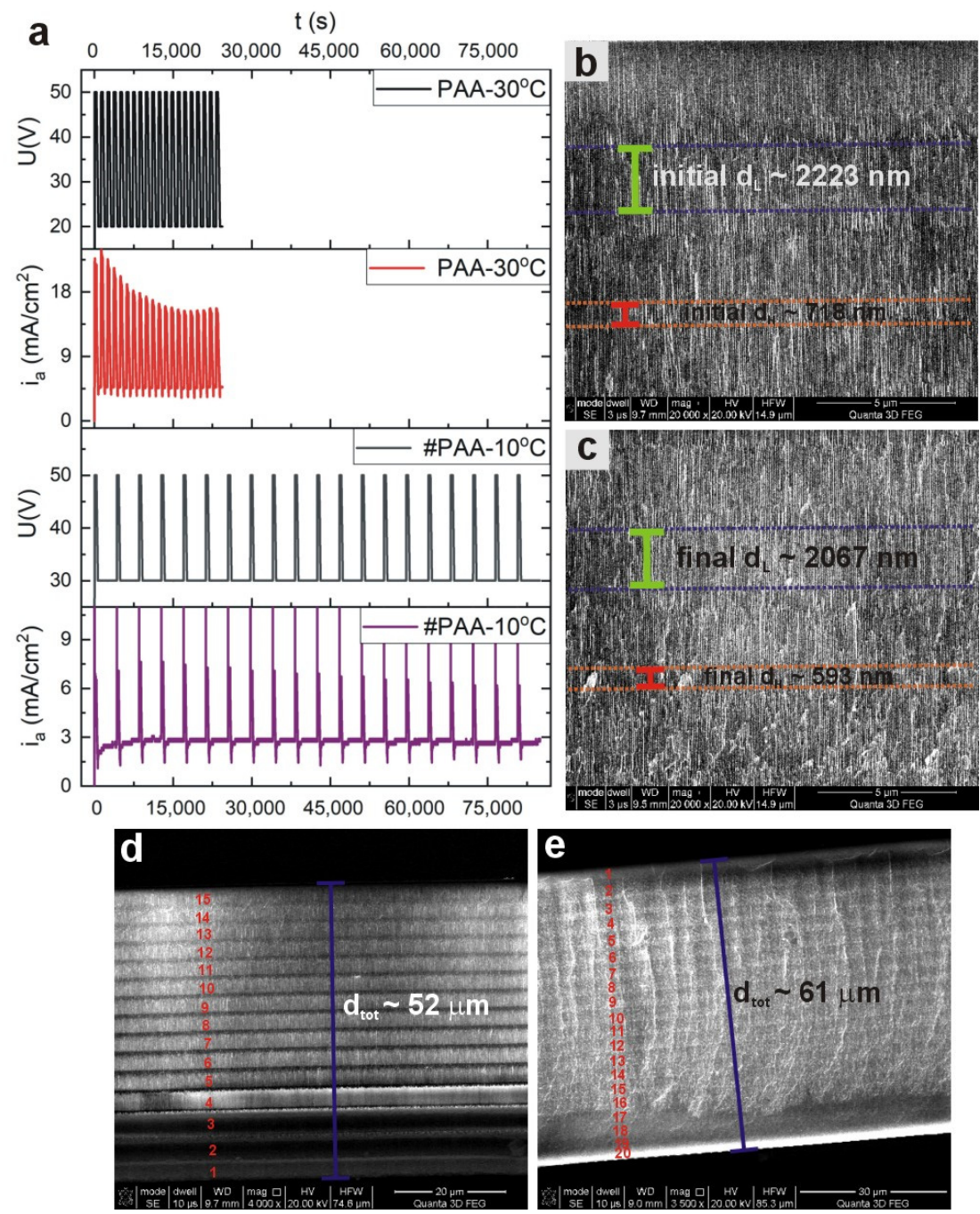

Figure 4. $i_{a}(t)$ curves recorded during pulse anodization (20 cycles) of the sample PAA- $30{ }^{\circ} \mathrm{C}$ $\left(\mathrm{U}_{\mathrm{H}}=50 \mathrm{~V}\right.$ with $\mathrm{t}_{\mathrm{H}}=360 \mathrm{~s}, \mathrm{U}_{\mathrm{L}}=20 \mathrm{~V}$ with $\mathrm{t}_{\mathrm{L}}=480 \mathrm{~s}$. at $\left.30^{\circ} \mathrm{C}\right)$ and \#PAA- $10{ }^{\circ} \mathrm{C}\left(\mathrm{U}_{\mathrm{H}}=50 \mathrm{~V}\right.$ with $\mathrm{t}_{\mathrm{H}}=360 \mathrm{~s}, \mathrm{U}_{\mathrm{L}}=30 \mathrm{~V}$ with $\mathrm{t}_{\mathrm{L}}=3600 \mathrm{~s}$. at $\left.10^{\circ} \mathrm{C}\right)(\mathbf{a})$; SEM images of initial $(\mathbf{b})$ and final $(\mathbf{c}) \mathrm{d}_{\mathrm{H}}$ and $\mathrm{d}_{\mathrm{L}}$ segments in the sample \#PAA $-10{ }^{\circ} \mathrm{C}$; SEM image of a cross-sectional view of the whole PAA- $30{ }^{\circ} \mathrm{C}$ (d) and \#PAA- $10^{\circ} \mathrm{C}$ (e) membranes.

In Figure 5, transmission spectra of the PAA-based DBR structures fabricated at the temperature range $5-30{ }^{\circ} \mathrm{C}$ are presented. The position of photonic stop bands (PSBs) is usually determined based on Bragg-Snell law [47]

$$
m \lambda=2 d \sqrt{n_{e f f}^{2}-n_{\text {air }}^{2} \sin ^{2} \theta}
$$

where $\lambda$ is the wavelength of a stop band, $m$ is the order of the PSB, $d$ is the layer thickness (periodicity), $\theta$ is the angle of incidence, $n_{\text {eff }}$ is the effective refractive index, and $n_{\text {air }}$ is the refractive index of air. 
In the transmission spectra $(\mathrm{T}(\lambda))$ several resonance peaks are visible which can be assigned to different orders of a given stop band $\left(\lambda_{i}, \mathrm{i}=1-4\right.$, correspond to 1-4 orders of PSB; the bands were assigned to the $\lambda_{i}$ based on the Bragg-Snell equation, assuming $\theta \sim 0$ ). At temperatures $5^{\circ} \mathrm{C}$ and $10^{\circ} \mathrm{C}$, the peaks are distinct and narrow. As compared to the PSBs in the sample PAA $-5{ }^{\circ} \mathrm{C}$, the peaks in the spectrum of the sample PAA $-10^{\circ} \mathrm{C}$ are more intensive and red-shifted. Upon increasing temperature, the peaks shift further towards the red part of the spectrum, split, and become progressively broadened. In the spectrum of the PAA $-25^{\circ} \mathrm{C}$ they almost disappear. However, in the spectrum of the sample PAA $-30^{\circ} \mathrm{C}$ the peaks start to show up again: several low-order ones with lower intensity in the range 1000-2500 $\mathrm{nm}$, and one located in the mid-infrared region, centered at $\sim 4386 \mathrm{~nm}$ with $\mathrm{T} \sim 0.20$ (according to a commonly used subdivision scheme MIR region falls into 3-8 $\mu \mathrm{m}$ [48]). The stop band in the MIR region (assigned to $\lambda_{2}$ of the PSB) is very symmetric, what usually indicates a good quality photonic crystal structure. Moreover, based on the Bragg-Snell equation (for $\theta \sim 0$ ) and taking into account the measured periodicity $\left(d=\mathrm{d}_{\mathrm{H}}+\mathrm{d}_{\mathrm{L}}\right)$ and $\lambda_{\mathrm{i}}$, the $n_{\text {eff }}$ of the studied PAA-based DBRs can be roughly estimated to be within the range of 1.13-1.57.

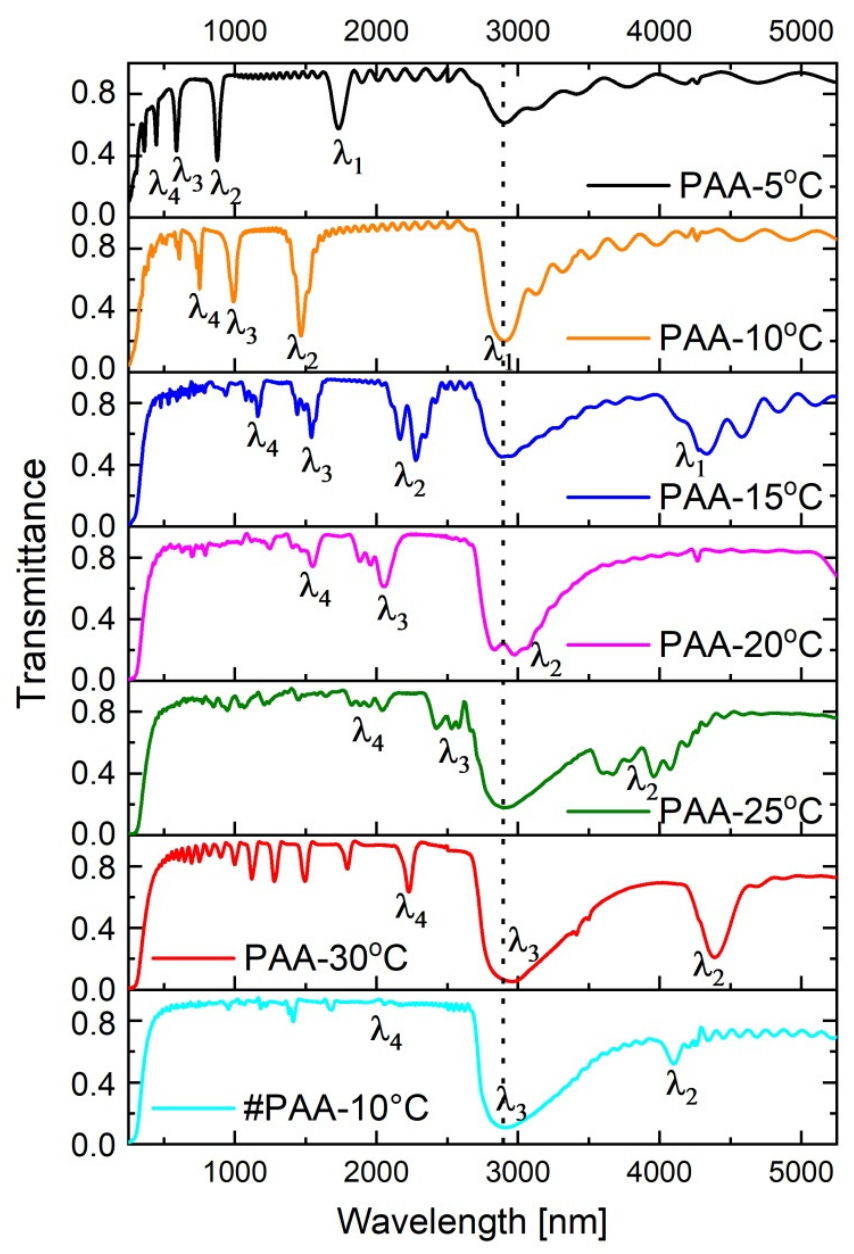

Figure 5. Transmittance spectra of PAA-based photonic structures anodized at temperature range 5-30 ${ }^{\circ} \mathrm{C}$ (the broad peak at around $3000 \mathrm{~nm}$, present in all spectra and marked by vertical, black, dotted line, originate from $\mathrm{OH}$ group vibrations of adsorbed water [49]).

The spectrum of the \# PAA $-10{ }^{\circ} \mathrm{C}$ DBR is quite similar to the one of the sample PAA- $30{ }^{\circ} \mathrm{C}$ in terms that it also shows several bands in the range 1000-2500 nm, and the one in the MIR region. The peaks are, however, much less intensive (the $\lambda_{2}$ band is located at around $4100 \mathrm{~nm}$ with T 0.5). 
The PAA $-30^{\circ} \mathrm{C}$ photonic crystal apparently has much better optical properties than the \#PAA-10 ${ }^{\circ} \mathrm{C}$ crystal, despite its lower number of $\mathrm{d}_{\mathrm{L}}$ and $\mathrm{d}_{\mathrm{H}}$ layers and larger difference in the initial and final thickness of the $d_{L}$ and $d_{H}$ layers. This phenomena can be due, however, to a larger refractive index contrast $\left(\Delta n_{\text {eff }}\right)$ between the subsequent $\mathrm{d}_{\mathrm{L}}$ and $\mathrm{d}_{\mathrm{H}}$ segments. It was shown before that a stopband enlarges and sharpens when the $\Delta n_{\text {eff }}$ increases [20]. The $\Delta n_{\text {eff }}$ in PAA photonic material is directly related with porosity contrast $(\Delta P)$ between the $\mathrm{d}_{\mathrm{L}}$ and $\mathrm{d}_{\mathrm{H}}$ layers [21], and the porosity, in turn, is determined by both anodizing voltage and temperature $[10,11]$ : the larger the applied voltage and the higher the temperature the greater is the porosity. Therefore, the $\Delta P$ in the sample PAA $-30^{\circ} \mathrm{C}$ is tuned and increased by both larger $\mathrm{U}_{\mathrm{H}}-\mathrm{U}_{\mathrm{L}}$ contrast $(30 \mathrm{~V})$ and higher anodizing temperature $\left(\mathrm{T}=30^{\circ} \mathrm{C}\right)$ as compared to the lower $\mathrm{U}_{\mathrm{H}}-\mathrm{U}_{\mathrm{L}}$ contrast $(20 \mathrm{~V})$ and lower temperature $\left(\mathrm{T}=10^{\circ} \mathrm{C}\right)$ applied to fabricate the sample \#PAA- $10^{\circ} \mathrm{C}$.

Morphology analysis of the PAA- $30{ }^{\circ} \mathrm{C}$ DBR crystal suggests that its optical properties can be still improved by a better tailoring the $\mathrm{d}_{\mathrm{H}}$ and $\mathrm{d}_{\mathrm{L}}$ interfaces. In Figure 6, it can be noticed that the edge of the $d_{H}$ segment that corresponds with the gradual decrease of voltage from $U_{H}$ to $U_{L}\left(U_{H} \rightarrow U_{L}\right.$ edge) is very blurred as compared to the opposite edge that corresponds with a direct voltage change from $U_{L}$ to $U_{H}\left(U_{L} \rightarrow U_{H}\right.$ edge). The clear and sharp interfaces between constitutive layers are known to be critical for highly reflective DBRs [50]. Therefore, the pulse sequence were modified accordingly by acceleration of the voltage drop rate in order to sharpen the $U_{H} \rightarrow U_{L}$ edge. In Figure $7, i_{a}(t)$ curves recorded during pulse anodization $\left(\mathrm{U}_{\mathrm{H}}=50 \mathrm{~V}\right.$ with $\mathrm{t}_{\mathrm{H}}=360 \mathrm{~s}, \mathrm{U}_{\mathrm{L}}=20 \mathrm{~V}$ with $\mathrm{t}_{\mathrm{L}}=480 \mathrm{~s}, 20$ cycles, $\mathrm{T}=30^{\circ} \mathrm{C}$ ) with increasing $\mathrm{U}_{\mathrm{H}} \rightarrow \mathrm{U}_{\mathrm{L}}$ drop rate from $0.078 \mathrm{~V} / \mathrm{s}$ up to $0.312 \mathrm{~V} / \mathrm{s}$ are shown, along with the corresponding transmission spectra (the samples: PAA $-30{ }^{\circ} \mathrm{C} \_0.078$, PAA $-30{ }^{\circ} \mathrm{C} \_0.156$, PAA -30 ${ }^{\circ} \mathrm{C} \_0.234$, and PAA— $30{ }^{\circ} \mathrm{C} \_0.312$, respectively).

It can be seen that upon decreasing the $\mathrm{U}_{\mathrm{H}} \rightarrow \mathrm{U}_{\mathrm{L}}$ rate from $0.0718 \mathrm{~V} / \mathrm{s}$ to $0.234 \mathrm{~V} / \mathrm{s}$ the intensity of the corresponding transmission dips $\left(\lambda_{2}\right.$ and $\left.\lambda_{3}\right)$ increases. The intensity of the $\lambda_{2}$ band in the PAA-30 ${ }^{\circ} \mathrm{C} \_0.078$ sample increases from 0.20 to 0.10 for the sample PAA- $30{ }^{\circ} \mathrm{C} \_0.156$ and to 0.08 for the sample PAA- $30{ }^{\circ} \mathrm{C} \_0.234$. At the same time, the $\lambda_{2}$ shifts from $4386 \mathrm{~nm}$ to $3587 \mathrm{~nm}$ and $3602 \mathrm{~nm}$ in the samples anodized with the lower $\mathrm{U}_{\mathrm{H}} \rightarrow \mathrm{U}_{\mathrm{L}}$ rate $(0.156 \mathrm{~V} / \mathrm{s}$ and $0.234 \mathrm{~V} / \mathrm{s}$, respectively). Furthermore, the decrease of the $\mathrm{U}_{\mathrm{H}} \rightarrow \mathrm{U}_{\mathrm{L}}$ rate to $0.312 \mathrm{~V} / \mathrm{s}$ deteriorates the optical properties of the PAA $-30{ }^{\circ} \mathrm{C} \_0.312$ DBR: the resonance peaks split and become hardly distinguishable.

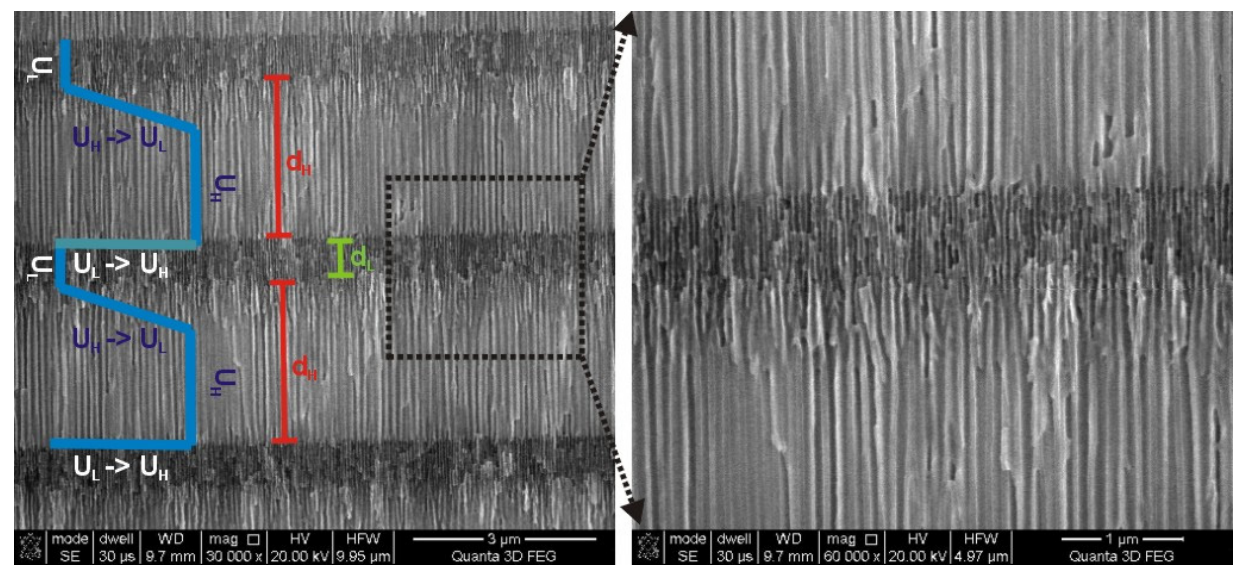

Figure 6. The $U_{H} \rightarrow U_{L}$ and $U_{L} \rightarrow U_{H}$ interfaces in the PAA $-30{ }^{\circ} \mathrm{C}$ DBR. 

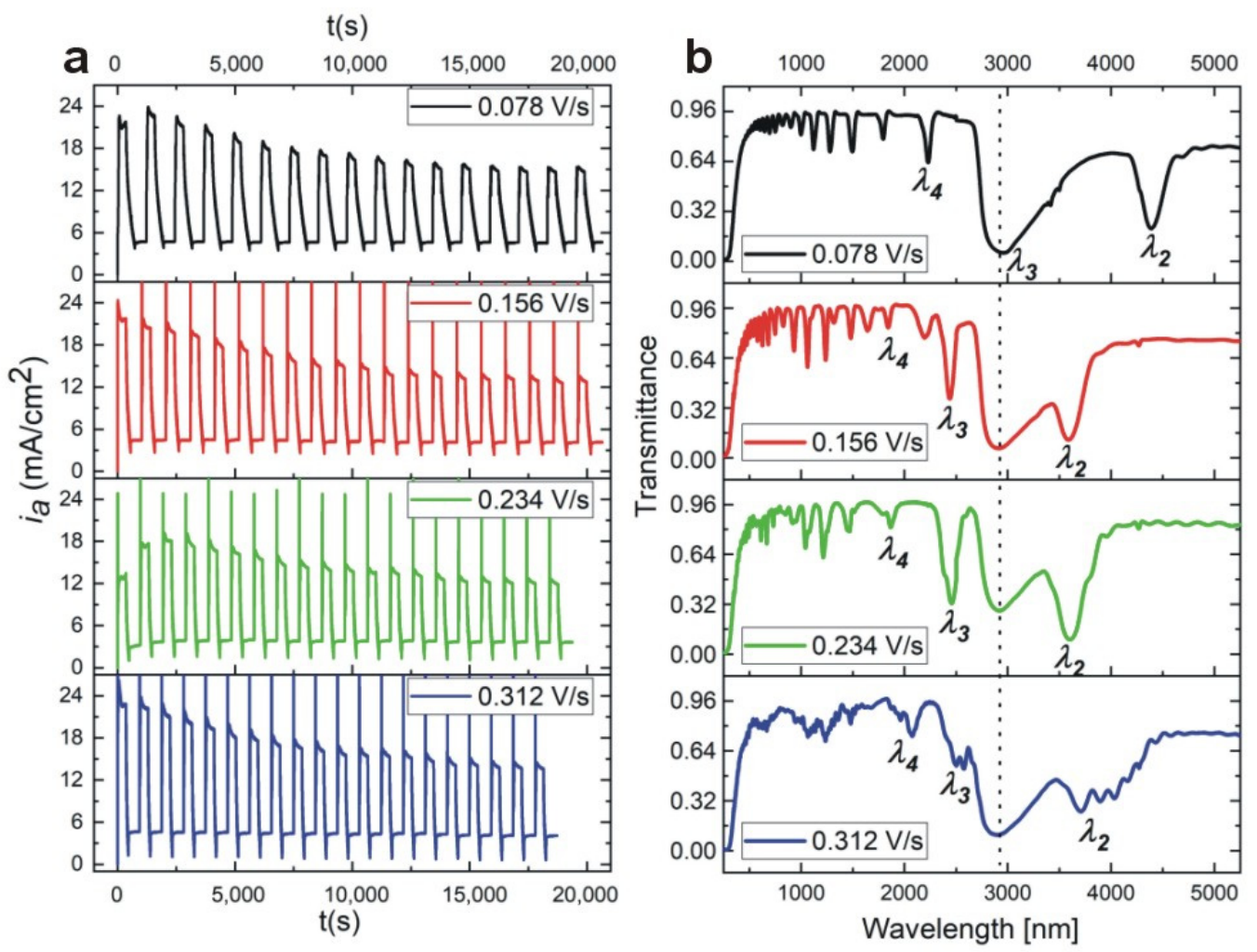

Figure 7. $i_{a}(t)$ curves recorded during pulse anodization $\left(\mathrm{U}_{\mathrm{H}}=50 \mathrm{~V}\right.$ with $\mathrm{t}_{\mathrm{H}}=360 \mathrm{~s}, \mathrm{U}_{\mathrm{L}}=20 \mathrm{~V}$ with $\mathrm{t}_{\mathrm{L}}$ $=480 \mathrm{~s}, 20$ cycles, at $30^{\circ} \mathrm{C}$ ) with decreasing $\mathrm{U}_{\mathrm{H}} \rightarrow \mathrm{U}_{\mathrm{L}}$ drop rate form $0.078 \mathrm{~V} / \mathrm{s}$ down to $0.312 \mathrm{~V} / \mathrm{s}(\mathbf{a})$, the corresponding transmission spectra (the broad peak at around $3000 \mathrm{~nm}$ present in all spectra and marked by vertical, black, dotted line, originate from $\mathrm{OH}$ group vibrations of adsorbed water [49]) (b).

The shift of the $\lambda_{i}$ to shorter wavelength is presumably caused by the reduced thickness of both $d_{H}$ and $d_{L}$ layers formed in the PAA $-30{ }^{\circ} \mathrm{C}$ DBR crystals prepared under the slower $U_{H} \rightarrow U_{L}$ rates (Figure 8a). In Figure $8 \mathrm{~b}-\mathrm{d}$, SEM images of cross-sectional views of the whole PAA membranes, prepared under various $U_{H} \rightarrow U_{L}$ rates, are shown. It can be observed that the number of $d_{H}$ and $d_{L}$ segments increases as the $\mathrm{U}_{\mathrm{H}} \rightarrow \mathrm{U}_{\mathrm{L}}$ rate decreases (Figure $8 \mathrm{~b}-\mathrm{d}$ ). In the sample PAA- $30{ }^{\circ} \mathrm{C} \_0.312$ almost all segments (19 out of 20 ) were formed. The $d_{\text {tot }}$ varies also with the $U_{H} \rightarrow U_{L}$ rate, but does not exceed $54 \mu \mathrm{m}$ for the PAA- $30{ }^{\circ} \mathrm{C} \_0.312$ sample. It seems thus that the $54 \mu \mathrm{m}$ is indeed a limit thickness for PAA-based DBR grown at $30^{\circ} \mathrm{C}$. On the other hand, it can be expected that lowering $\mathrm{T}$ by few degrees (between $26^{\circ} \mathrm{C}$ and $29^{\circ} \mathrm{C}$ ) will help to prepare DBR built out of full $20 \mathrm{~d}_{\mathrm{H}}$ and $\mathrm{d}_{\mathrm{L}}$ segments. This, in turn, will contribute to optimization of the photonic characteristics of PAA-based DBR with PSB resonances in MIR. Summarizing: the better optical quality of the samples PAA-30 ${ }^{\circ} \mathrm{C} \_0.156$ and PAA $-30{ }^{\circ} \mathrm{C}_{-} 0.234$ DBRs as compared to that of the PAA- $30^{\circ} \mathrm{C}_{-} 0.078$ sample is caused by a larger number of constitutive $d_{H}$ and $d_{L}$ layers and by much sharper interfaces between $d_{H}$ and $d_{L}$ layers from the $\mathrm{U}_{\mathrm{H}} \rightarrow \mathrm{U}_{\mathrm{L}}$ side (Figure 8e-h). Apparently, the transmission spectra of the PAA-30 ${ }^{\circ} \mathrm{C} \_0.312$ DBR deteriorates owing to the large difference between initial and final $d_{H}$ thickness (Figure 8a), which eliminates potential benefits emerging from the largest number of subsequent $d_{H}$ and $d_{L}$ segments among all PAA-based DBRs fabricated at $30^{\circ} \mathrm{C}$. 

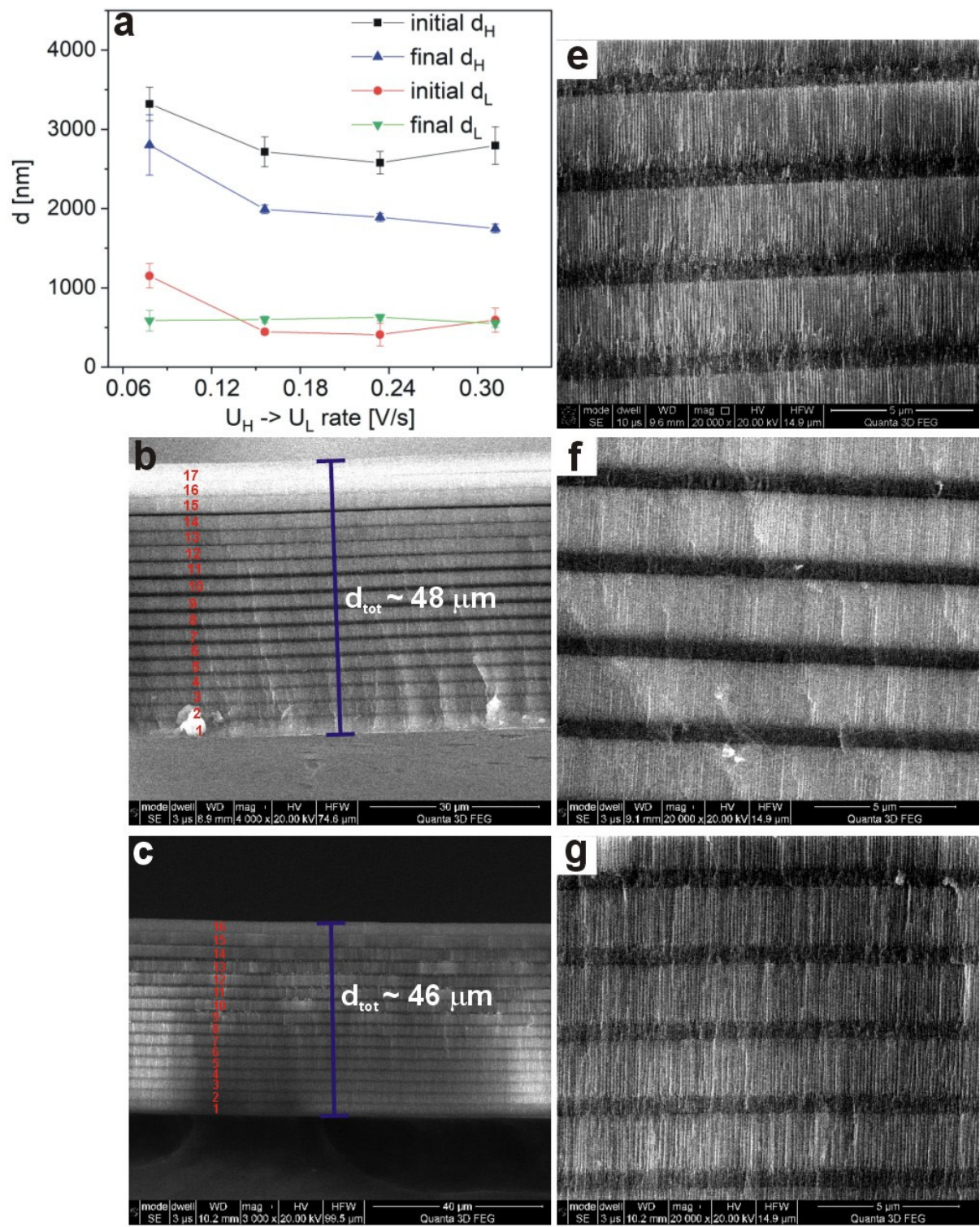

d
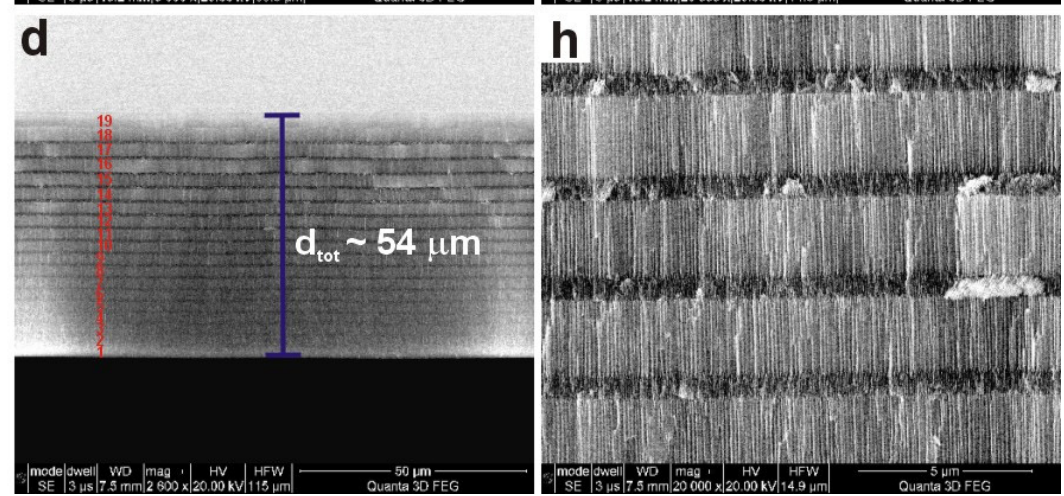

Figure 8. Thickness of $d_{H}$ and $d_{L}$ segments as a function of the $U_{H} \rightarrow U_{L}$ drop rate (a); SEM images of a cross-sectional view of the whole PAA $-30{ }^{\circ} \mathrm{C} \_0.156$ (b), PAA $-30{ }^{\circ} \mathrm{C} \_0.234$ (c), and PAA-30 ${ }^{\circ} \mathrm{C} \_0.312$ (d) membrane; SEM images of middle $\mathrm{d}_{\mathrm{H}}$ and $\mathrm{d}_{\mathrm{L}}$ layers of the PAA-30 ${ }^{\circ} \mathrm{C}$ DBRs with $\mathrm{U}_{\mathrm{H}} \rightarrow$ $\mathrm{U}_{\mathrm{L}}$ rate of $0.078 \mathrm{~V} / \mathrm{s}(\mathbf{e}), 0.156 \mathrm{~V} / \mathrm{s}(\mathbf{f}), 0.234 \mathrm{~V} / \mathrm{s}(\mathbf{g})$, and $0.312 \mathrm{~V} / \mathrm{s}(\mathbf{h})$.

Based on transmission spectra in Figure 2, it can be stated that the strongest PSBs were generated in the PAA-based DBR fabricated at $10^{\circ} \mathrm{C}$. Therefore this temperature was selected to study the influence 
of $\mathrm{U}_{\mathrm{H}}$ and $\mathrm{U}_{\mathrm{L}}$ voltage on the optical properties of the PCs. In Figure $9 \mathrm{a}$, the $i_{a}(t)$ curves for the DBRs synthesized under different values of $U_{\mathrm{H}}(50 \mathrm{~V}, 45 \mathrm{~V}, 40 \mathrm{~V})$ and $\mathrm{U}_{\mathrm{L}}(20 \mathrm{~V}, 30 \mathrm{~V})$ are demonstrated, with other conditions kept as previously (the samples: PAA-10 ${ }^{\circ} \mathrm{C} \_50-20$, PAA $-10{ }^{\circ} \mathrm{C} \_45-20$, PAA -10 ${ }^{\circ} \mathrm{C}_{-} 40-20$, and PAA- $10{ }^{\circ} \mathrm{C} \_50-30$, respectively). It can be observed that whereas the $i_{a}{ }^{\max }$ decreases slowly with pulse cycles during anodization of the PAA-10 ${ }^{\circ} \mathrm{C} \_50-20$ and PAA- $10{ }^{\circ} \mathrm{C} \_45-20 \mathrm{DBRs}$, in the anodization of the PAA-10 $1{ }^{\circ} \mathrm{C} \_40-20$ sample the $i_{a}{ }^{m a x}$ remains perfectly stable during all 20 cycles. The largest $i_{a}{ }^{\max }$ drop is recorded for the PAA-10 ${ }^{\circ} \mathrm{C} \_50-30$ sample. The current evolution is reflected in the difference between initial and final thickness of $d_{H}$ and $d_{L}$ segments: for all PAA-based DBRs the difference is discernable, whereas in the DBR prepared under the $40-20 \mathrm{~V}$ all $\mathrm{d}_{\mathrm{H}}$ and $\mathrm{d}_{\mathrm{L}}$ layers are identical (Figure 9b). Particularly interesting is the comparison between the PAA-10 ${ }^{\circ} \mathrm{C} \_40-20$ and PAA-10 ${ }^{\circ} \mathrm{C} \_50-30$ samples. Despite the same $\mathrm{U}_{\mathrm{H}}-\mathrm{U}_{\mathrm{L}}$ contrast $(20 \mathrm{~V})$, the current behavior and the resulting DBR are quite different.

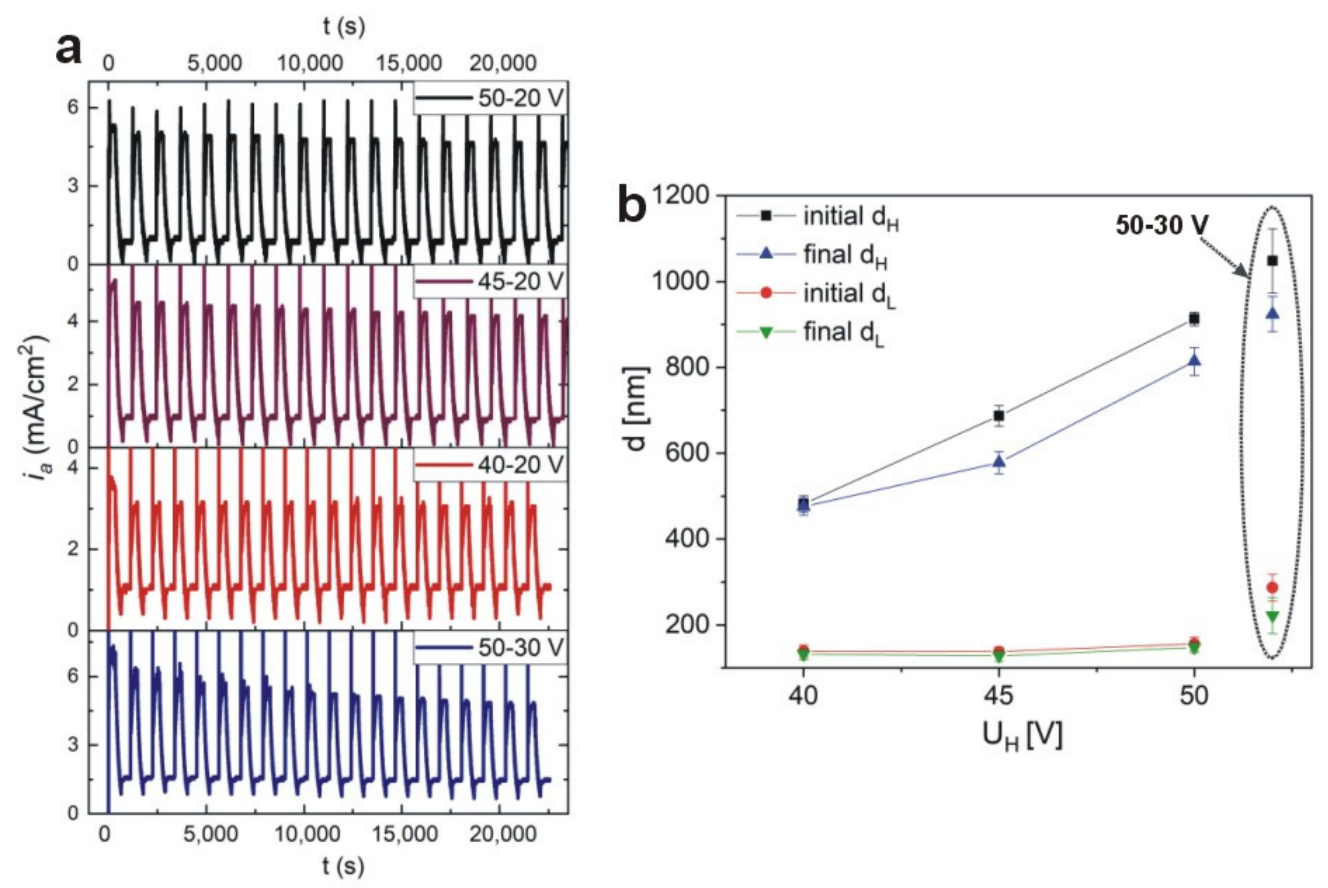

Figure 9. Current density $i_{a}(t)$ recorded during pulse anodization of aluminum under the following $\mathrm{U}_{\mathrm{H}}-\mathrm{U}_{\mathrm{L}}$ potentials: $50-20 \mathrm{~V}, 45-20 \mathrm{~V}, 40-20 \mathrm{~V}$, and $50-30 \mathrm{~V}\left(\mathrm{t}_{\mathrm{H}}=360 \mathrm{~s}, \mathrm{t}_{\mathrm{L}}=480 \mathrm{~s}, 20\right.$ cycles, $\left.10{ }^{\circ} \mathrm{C}\right)(\mathbf{a})$; initial and final $d_{H}$ and $d_{L}$ thickness as a function of $U_{H}$ for the $U_{L}=20 \mathrm{~V}$ (the $d_{H}$ and $d_{L}$ thickness determined for the PAA- $10{ }^{\circ} \mathrm{C} \_50-30$ sample is placed in the graph in a dotted ellipse) (b).

The transmission spectrum of the PAA $-10^{\circ} \mathrm{C}$ sample is compared with $\mathrm{T}(\lambda)$ spectra of the other DBRs prepared at $10^{\circ} \mathrm{C}$ in Figure 10, in the $250-2500 \mathrm{~nm}$ spectral range. First of all, upon decreasing $\mathrm{U}_{\mathrm{H}}$ the PSBs are shifted towards blue part of the spectrum, mostly as an effect of decreasing the $\mathrm{d}_{\mathrm{H}}$ layer thickness (Figure $9 \mathrm{~b}$ ). The intensity of the resonance peaks decreases progressively, however, the PSBs in the samples PAA- $10{ }^{\circ} \mathrm{C}_{-} 45-20$ and PAA- $10{ }^{\circ} \mathrm{C}_{-} 40-20$ become more symmetric and narrower as compared to the PSB in the sample PAA-10 ${ }^{\circ} \mathrm{C} \_50-20$. The narrower and more symmetric peaks, in turn, indicate better quality of the DBR crystals. In the $\mathrm{T}(\lambda)$ spectra of the PAA-10 ${ }^{\circ} \mathrm{C} \_50-30$ sample the PSBs have gone, meaning that basically no DBR structure was formed under this condition. Larger intensity of the resonance peaks in the $\mathrm{T}(\lambda)$ spectrum of the PAA-10 ${ }^{\circ} \mathrm{C} \_50-20 \mathrm{DBR}$ can be associated with a larger $\mathrm{U}_{\mathrm{H}}-\mathrm{U}_{\mathrm{L}}$ contrast $(30 \mathrm{~V})$ and consequently larger $\Delta P$. However, owing to the larger $\mathrm{U}_{\mathrm{H}}-\mathrm{U}_{\mathrm{L}}$ contrast, the current recovery $\left(i_{a}{ }^{m a x}\right)$ after application of the following $\mathrm{U}_{\mathrm{H}}$ pulses gets gradually weakened, and consequently, the formed $\mathrm{d}_{\mathrm{H}}$ and $\mathrm{d}_{\mathrm{L}}$ segments are not perfectly uniform throughout the whole PAA membrane. This, in turn, broadens the transmission peaks. As the $\mathrm{U}_{\mathrm{H}}-\mathrm{U}_{\mathrm{L}}$ contrast 
decreases (due to $\mathrm{U}_{\mathrm{H}}$ decrease), the $i_{a}{ }^{\text {max }}$ becomes equalized (in the sample PAA-10 ${ }^{\circ} \mathrm{C} \_40-20$ the $i_{a}{ }^{m a x}$ is perfectly even) and the structural and optical properties of DBR are improved: the transmission peaks become narrower and more symmetric. However, the lower $\mathrm{U}_{\mathrm{H}}-\mathrm{U}_{\mathrm{L}}$ contrast makes the PSB peaks less intensive owing to the smaller $\Delta P$.

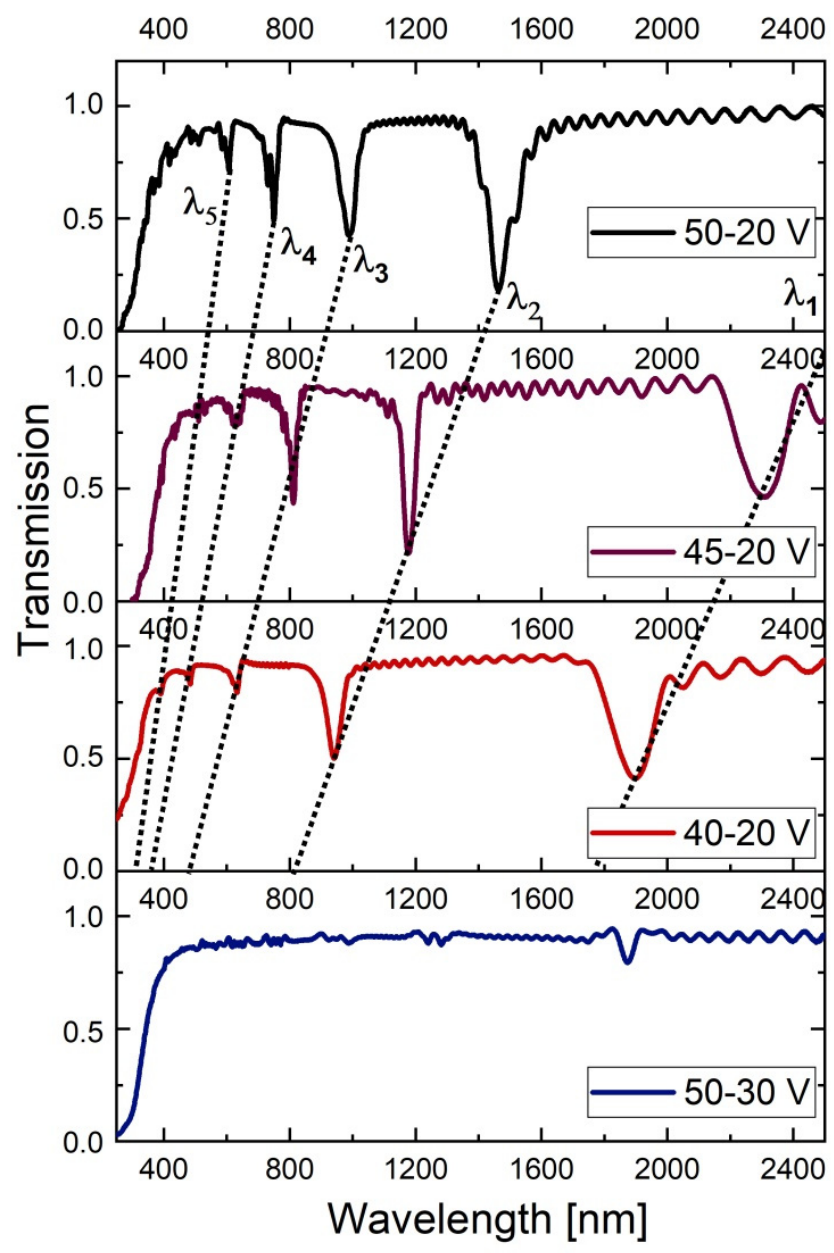

Figure 10. Transmittance spectra of PAA-based DBR fabricated at $10{ }^{\circ} \mathrm{C}$ under various $\mathrm{U}_{\mathrm{H}}$ and $\mathrm{U}_{\mathrm{L}}$ values.

Summarizing, when the $\mathrm{U}_{\mathrm{H}}$ is lowered from $50 \mathrm{~V}$ to $40 \mathrm{~V}$ (while keeping the $\mathrm{U}_{\mathrm{L}}$ constant) the quality of the crystals remains quite stable (or even improves). However, when the $U_{L}$ values is increased from $20 \mathrm{~V}$ to $30 \mathrm{~V}$ (while keeping the $\mathrm{U}_{\mathrm{H}}$ constant) the crystal quality is lost. The latter is caused by both small $\Delta P$ and the large $i_{a}{ }^{m a x}$ drop upon subsequent application of the $\mathrm{U}_{\mathrm{H}}$ pulses. Based on these data, one can risk the statement that a contrast between high and low potential pulses (and thus $\Delta P$ ) is less important than the steady current recovery. This statement can be also partially supported by the observation that the sample prepared under a larger $\mathrm{U}_{\mathrm{H}}-\mathrm{U}_{\mathrm{L}}$ contrast but lower anodizing temperature (the PAA $-5{ }^{\circ} \mathrm{C}$ sample) is characterized by a comparable optical quality than the one fabricated under the lower $\mathrm{U}_{\mathrm{H}}-\mathrm{U}_{\mathrm{L}}$ contrast (the sample anodized under 40-20 V) but at higher anodizing temperature. In the latter case, however, most likely the higher temperature is the factor that improves structural (better regularity and circularity of pores) and thus optical properties PAA-based DBR. 


\section{Conclusions}

In this work, the influence of anodization temperature from $5^{\circ} \mathrm{C}$ to $30^{\circ} \mathrm{C}$ range on the growth and photonic properties of PAA-based DBRs was studied. Transmission spectra were recorded to determine the position and a shape of PSBs. It was observed that above $10{ }^{\circ} \mathrm{C}$ and up to $25^{\circ} \mathrm{C}$ the PSB properties strongly deteriorate as manifested in a progressive decrease, widening, and splitting of transmission peaks. However, at $30{ }^{\circ} \mathrm{C}$ the PSBs appeared again with several narrow, low intensity peaks in the 1000-2500 nm range and a strong, symmetric resonance peak in the MIR region. The photonic properties of the PAA $-30^{\circ} \mathrm{C}$ DBR were further improved by a small modification of the pulse sequence which sharpened the interface between $d_{H}$ and $d_{L}$ segments. Moreover, it was shown that larger $U_{H}-U_{L}$ contrast helps to increase the intensity of respective PSBs owing to the larger porosity contrast $(\Delta P)$ between consecutive low and high RI layers. However, the larger $\mathrm{U}_{\mathrm{H}}-\mathrm{U}_{\mathrm{L}}$ contrast slowed down the current recovery $\left(i_{a}{ }^{m a x}\right)$ after application of subsequent $\mathrm{U}_{\mathrm{H}}$ pulses. Generally, $\mathrm{U}_{\mathrm{H}}-\mathrm{U}_{\mathrm{L}}$ contrast seems to be less important than a steady $i_{a}{ }^{\max }$ during application of consecutive pulses. Structural and optical properties of DBR anodized under $40-20 \mathrm{~V}$ at $10{ }^{\circ} \mathrm{C}$ were much better than the properties of the DBR synthesized under $50-30 \mathrm{~V}$, despite the same $\mathrm{U}_{\mathrm{H}}-\mathrm{U}_{\mathrm{L}}$ contrast $(20 \mathrm{~V})$. On the other hand, the properties were comparable with that of the DBR synthesized under $50-20 \mathrm{~V}\left(\mathrm{U}_{\mathrm{H}}-\mathrm{U}_{\mathrm{L}}\right.$ contrast $\left.=30 \mathrm{~V}\right)$, but at lower temperature of $5{ }^{\circ} \mathrm{C}$. This means also that the temperature is an important factor in tailoring good quality PCs. Furthermore, the analysis performed in this work revealed that anodization at high temperature provides new conditions for designing and tailoring the PAA-based photonic structures with good photonic properties in MIR region. In fact, this was a first time the PAA-based DBR structure with a good quality PSB (relatively narrow and symmetric peak) in the MIR spectral range was fabricated. The new conditions provided by the high-temperature-pulse-anodization needs further optimization and mastering the electrochemical process (e.g., process conducted at $\mathrm{T}=26-29^{\circ} \mathrm{C}$, various duration of $U_{H}$ and $U_{L}$ pulses, various $U_{H}-U_{L}$ contrast) in order to produce PAA-based photonic structure with excellent photonic properties (strong and narrow PSB resonances) in the MIR spectral range. This work is in progress.

Author Contributions: Conceptualization, M.N.; Electrochemical synthesis of PAA-based PCs, E.B.; Transmission measurements, M.W.; SEM analysis, M.N.; Writing—original draft preparation, M.N.; All authors have read and agreed to the published version of the manuscript.

Funding: The research was financed by National Science Centre, Poland (UMO-2019/35/B/ST5/01025). The work was also supported by the statutory research funds of the Department of Functional Materials and Hydrogen Technology, Military University of Technology, Warsaw, Poland. The UV-vis-NIR spectrometers used in these studies were obtained with funds from the Polish Ministry of Science and Higher Education grant for investment in large research infrastructure no. 7044/IA/SP/2019.

Conflicts of Interest: The authors declare no conflict of interest.

\section{References}

1. Jani, A.M.; Losic, D.; Voelcker, N.H. Nanoporous anodic aluminium oxide: Advances in surface engineering and emerging applications. Progr. Mater. Sci. 2013, 58, 636-704. [CrossRef]

2. Lee, W.; Park, S.-J. Porous anodic aluminium oxide: Anodization and templated synthesis of functional nanostructures. Chem. Rev. 2014, 114, 7487-7556. [CrossRef] [PubMed]

3. Pashchanka, M.; Schneider, J.J. Self-ordering regimes of porous anodic alumina layers formed in highly diluted sulfuric acid electrolytes. J. Phys. Chem. C 2016, 120, 14590-14596. [CrossRef]

4. Li, F.; Zhang, L.; Metzger, R.M. On the growth of highly ordered pores in anodized aluminium oxide. Chem. Mater. 1998, 10, 2470-2480. [CrossRef]

5. Ono, S.; Saito, M.; Ishiguro, M.; Asoh, H. Controlling factor of self-ordering of anodic porous alumina. J. Electrochem. Soc. 2004, 151, B473-B478. [CrossRef]

6. Ono, S.; Saito, M.; Asoh, H. Self-ordering of anodic porous alumina induced by local current concentration: Burning. Electrochem. Solid State Lett. 2004, 7, B21-B24. [CrossRef] 
7. Qin, X.; Zhang, J.; Meng, X.; Deng, C.; Zhang, L.; Ding, G.; Zeng, H.; Xu, X. Preparation and analysis of anodic aluminum oxide films with continuously tunable interpore distances. Appl. Surf. Sci. 2015, 328, 459-465. [CrossRef]

8. Akiya, S.; Kikuchi, T.; Natsui, S.; Sakaguchi, N.; Suzuki, R.O. Self-ordered porous alumina fabricated via phosphonic acid anodizing. Electrochim. Acta 2016, 190, 471-479. [CrossRef]

9. Kikuchi, T.; Nishinaga, O.; Natsui, S.; Suzuki, R.O. Fabrication of self-ordered porous alumina via etidronic acid anodizing and structural color generation from submicrometer-scale dimple array. Electrochim. Acta 2015, 156, 235-243. [CrossRef]

10. Zaraska, L.; Stępniowski, W.J.; Ciepiela, E.; Sulka, G.D. The effect of anodizing temperature on structural features and hexagonal arrangement of nanopores in alumina synthesized by two-step anodizing in oxalic acid. Thin Solid Films 2013, 534, 155-161. [CrossRef]

11. Stępniowski, W.J.; Bojar, Z. Synthesis of anodic aluminum oxide (AAO) at relatively high temperatures. Study of the influence of anodization conditions on the alumina structural features. Surf. Coat. Technol. 2011, 206, 265-272. [CrossRef]

12. Nielsch, K.; Choi, J.; Schwirn, K.; Wehrspohn, R.B.; Gosele, U. Self-ordering regimes of porous alumina: The $10 \%$ porosity rule. Nano Lett. 2002, 2, 677-680. [CrossRef]

13. Ikeda, H.; Iwai, M.; Nakajima, D.; Kikuchi, T.; Natsui, S.; Sakaguchi, N.; Suzuki, R.O. Nanostructural characterization of ordered gold particle arrays fabricated via aluminum anodizing, sputter coating, and dewetting. Appl. Surf. Sci. 2019, 465, 747-753. [CrossRef]

14. Norek, M.; Putkonen, M.; Zaleszczyk, W.; Budner, B.; Bojar, Z. Morphological, structural, and optical characterization of $\mathrm{SnO} 2$ nanotube arrays fabricated using anodic alumina (AAO) template-assisted atomic layer deposition. Mater. Charact. 2018, 136, 52-59. [CrossRef]

15. Norek, M.; Zaleszczyk, W.; Łuka, G.; Budner, B.; Zasada, D. Tailoring UV emission from a regular array of $\mathrm{ZnO}$ nanotubes by the geometrical parameters of the array and $\mathrm{Al} 2 \mathrm{O} 3$ coating. Ceram. Intern. 2017, 43, 5693-5701. [CrossRef]

16. Chernova, E.; Petukhov, D.; Boytsova, O.; Alentiev, A.; Budd, B.; Yampolskii, Y.; Eliseev, A. Enhanced gas separation factors of microporous polymer constrained in the channels of anodic alumina membranes. Sci. Rep. 2016, 6, 31183. [CrossRef]

17. Poinern, E.; Ali, N.; Fawcett, D. Progress in nano-engineered anodic aluminium oxide membrane development. Materials 2011, 4, 487-526. [CrossRef] [PubMed]

18. Fernández-Menéndez, L.J.; González, A.S.; Vega, V.; De la Prida, V.M. Electrostatic supercapacitors by atomic layer deposition on nanoporous anodic alumina templates for environmentally sustainable energy storage. Coatings 2018, 8, 403. [CrossRef]

19. Pavesi, L. Porous silicon dielectric multilayers and microcavities. La Riv. Del Nuovo Cimento 1997, $20,1-76$. [CrossRef]

20. Starkey, T.; Vukusic, P. Light manipulation principles in biological photonic systems. Nanophotonics 2013, 2, 289-307. [CrossRef]

21. Sulka, G.D.; Hnida, K. Distributed Bragg reflector based on porous anodic alumina fabricated by pulse anodization. Nanotechnology 2012, 23, 075303. [CrossRef] [PubMed]

22. Zhang, Y.; Fu, Q.; Ge, J. Photonic sensing of organic solvents through geometric study of dynamic reflection spectrum. Nat. Commun. 2015, 6, 7510. [CrossRef] [PubMed]

23. Yang, D.; Tian, H.; Ji, Y. Nanoscale photonic crystal sensor arrays on monolithic substrates using side-coupled resonant cavity arrays. Opt. Express 2011, 19, 20023-20034. [CrossRef]

24. Zhang, Y.; Zhao, Y.; Lv, R. A review for optical sensors based on photonic crystal cavities. Sens. Actuators A 2015, 233, 374-389. [CrossRef]

25. Martín-Palma, R.J.; Torres-Costa, V.; Pantano, C.G. Distributed Bragg reflectors based on chalcogenide glasses for chemical optical sensing. J. Phys. D Appl. Phys. 2009, 42, 055109. [CrossRef]

26. Lee, W.; Kim, J.C. Highly Ordered porous alumina with tailor-made pore structures by pulse anodization. Nanotechnology 2010, 21, 485304. [CrossRef]

27. Chung, C.K.; Zhou, R.X.; Liu, T.Y.; Chang, W.T. Hybrid pulse anodization for the fabrication of porous anodic alumina films from commercial purity (99\%) aluminum at room temperature. Nanotechnology 2009, 20, 055301. [CrossRef] 
28. Chen, Y.; Santos, A.; Wang, Y.; Kumeria, T.; Li, J.; Wang, C.; Losic, D. Biomimetic nanoporius anodic alumina distributed Bragg reflectors in the form of films and microsized particles for sensing applications. ACS Appl. Mater. Interfaces 2015, 7, 19816-19824. [CrossRef]

29. Santos, A.; Yoo, J.H.; Rohatgi, C.V.; Kumeria, T.; Wang, Y.; Losic, D. Realisation and advanced engineering of true optical rugate filters based on nanoporous anodic alumina by sinusoidal pulse anodization. Nanoscale 2016, 8, 1360-1373. [CrossRef]

30. Santos, A.; Law, C.S.; Pereira, T.; Losic, D. Nanoporous hard data: Optical encoding of information within nanoporous anodic alumina photonic crystals. Nanoscale 2016, 8, 8091-8100. [CrossRef]

31. Law, C.S.; Santos, A.; Nemati, M.; Losic, D. Structural engineering of nanoporous anodic alumina photonic crystals by sawtooth-like pulse anodization. ACS Appl. Mater. Interfaces 2016, 8, 13542-13554. [CrossRef] [PubMed]

32. Santos, A.; Pereira, T.; Law, C.S.; Losic, D. Rational engineering of nanoporous anodic alumina optical bandpass filters. Nanoscale 2016, 8, 14846-14857. [CrossRef] [PubMed]

33. Wang, B.; Fei, G.T.; Wang, M.; Kong, M.G.; Zhang, L.D. Preparation of photonic crystals made of air pores in anodic alumina. Nanotechnology 2007, 18, 365601. [CrossRef]

34. Wang, Y.; Chen, Y.; Kumeria, T.; Ding, F.; Evdokiou, A.; Losic, D.; Santos, A. Facile synthesis of optical microcavities by a rationally designed anodization approach: Tailoring photonic signals by nanopore structure. ACS Appl. Mater. Interfaces 2015, 7, 9879-9888. [CrossRef] [PubMed]

35. Kumeria, T.; Rahman, M.M.; Santos, A.; Ferré-Borrull, J.; Marsal, L.F.; Losic, D. Nanoporous Anodic alumina rugate filters for sensing of ionic mercury: Toward environmental point-of-analysis systems. ACS Appl. Mater. Interfaces 2014, 6, 12971-12978. [CrossRef] [PubMed]

36. Kumeria, T.; Rahman, M.M.; Santos, A.; Ferré-Borrull, J.; Marsal, L.F.; Losic, D. Structural and optical nanoengineering of nanoporous anodic alumina rugate filters for real-time and label-free biosensing applications. Anal. Chem. 2014, 86, 1837-1844. [CrossRef] [PubMed]

37. Lee, W.; Schwirn, K.; Steinhart, M.; Pippel, E.; Scholz, R.; Gösele, U. Structural engineering of nanoporous anodic aluminium oxide by pulse anodization of aluminium. Nat. Nanotechnol. 2008, 3, 234-239. [CrossRef]

38. Zhang, S.; Xu, Q.; Feng, S.; Sun, C.; Peng, Q.; Lan, T. The effect of the voltage waveform on the microstructure and optical properties of porous anodic alumina photonic crystals. Opt. Mater. 2019, 98, 109488. [CrossRef]

39. Li, S.-Y.; Wang, J.; Wang, G.; Wang, J.-Z.; Wang, C.-W. Fabrication of one-dimensional alumina photonic crystals by anodization using a modified pulse-voltage method. Mater. Res. Bull. 2015, 68, 42-48. [CrossRef]

40. An, Y.-Y.; Wang, J.; Zhou, W.-M.; Jin, H.-X.; Li, J.-F.; Wang, C.-W. The preparation of high quality alumina defective photonic crystals and their application of photoluminescence enhancement. Superlattices Microstruct. 2018, 119, 1-8. [CrossRef]

41. Abbasimofrad, S.; Kashi, M.A.; Noormohammadi, M.; Ramazani, A. Tuning the optical properties of nanoporus anodic alumina photonic crystals of allowed voltage range via mixed acid concentration. J. Phys. Chem. Sol. 2018, 118, 221-231. [CrossRef]

42. Zheng, W.J.; Fei, G.T.; Wang, B.; Zhang, L.D. Modulation of transmission spectra of anodized alumina membrane distributed Bragg reflector by controlling anodization temperature. Nanoscale Res. Lett. 2009, 4, 665-667. [CrossRef] [PubMed]

43. Ferré-Borrull, J.; Rahman, M.M.; Pallarès, J.; Marsal, L.F. Tuning nanoporous anodic alumina distributed-Bragg reflectors with the number of anodization cycles and the anodization temperature. Nanoscale Res. Lett. 2014, 9, 416. [CrossRef] [PubMed]

44. Lee, W.; Ji, R.; Gösele, U.; Nielsch, K. Fast fabrication of long-range ordered porous alumina membranes by hard anodization. Nat. Mater. 2006, 5, 741-747. [CrossRef] [PubMed]

45. Yi, L.; Zhiyuan, L.; Xing, H.; Yisen, L.; Yi, C. Formation and microstructures of unique nanoporous AAO films fabricated by high voltage anodization. J. Mater. Chem. 2011, 21, 9661-9666. [CrossRef]

46. Yi, L.; Zhiyuan, L.; Xing, H.; Yisen, L.; Yi, C. Investigation of intrinsic mechanisms of aluminium anodization processes by analysing the current density. RSC Adv. 2012, 2, 5164-5171. [CrossRef]

47. Ozin, G.A.; Arsenault, A. Nanochemistry: A Chemical Approach to Nanomaterials, 2nd ed.; Royal Society of Chemistry: Cambridge, UK, 2015.

48. Byrnes, J. Unexploded Ordnance Detection and Mitigation, 1st ed.; Springer: Heidelberg, Germany, 2009; pp. 21-22. 
49. Włodarski, M.; Putkonen, M.; Norek, M. Infrared absorption study of Zn-S hybrid and ZnS ultrathin films deposited on poorus AAO ceramic support. Coatings 2020, 10, 459. [CrossRef]

50. Zhang, L.; Dong, K.; Chen, D.; Liu, Y.; Xue, J.; Lu, H.; Zhang, R.; Zheng, Y. Solar-blind ultraviolet AlInN/AlGaN distributed Bragg reflectors. Appl. Phys. Lett. 2013, 102, 242112. [CrossRef]

(C) 2020 by the authors. Licensee MDPI, Basel, Switzerland. This article is an open access article distributed under the terms and conditions of the Creative Commons Attribution (CC BY) license (http://creativecommons.org/licenses/by/4.0/). 